\title{
Peptide Fragmentation by Corona Discharge Induced Electrochemical Ionization
}

\author{
John R. Lloyd ${ }^{\mathrm{a}}$ and Sonja Hess ${ }^{\mathrm{b}}$ \\ ${ }^{a}$ Proteomics and Mass Spectrometry Facility, National Institute of Diabetes and Digestive and Kidney \\ Diseases, National Institutes of Health, Bethesda, Maryland, USA \\ b Proteome Exploration Laboratory, California Institute of Technology, Pasadena, California, USA
}

\begin{abstract}
Fundamental studies have greatly improved our understanding of electrospray, including the underlying electrochemical reactions. Generally regarded as disadvantageous, we have recently shown that corona discharge $(C D)$ can be used as an effective method to create a radical cation species $[\mathrm{M}]^{+}$, thus optimizing the electrochemical reactions that occur on the surface of the stainless steel (SS) electrospray capillary tip. This technique is known as CD initiated electrochemical ionization (CD-ECI). Here, we report on the fundamental studies using CD-ECI to induce analytically useful in-source fragmentation of a range of molecules that complex transition metals. Compounds that have been selectively fragmented using CD-ECI include enolate forming phenylglycine containing peptides, glycopeptides, nucleosides, and phosphopeptides. Collision induced dissociation (CID) or other activation techniques were not necessary for CD-ECI fragmentation. A four step mechanism was proposed: (1) complexation using either Fe in the SS capillary tip material or $\mathrm{Cu}(\mathrm{II})$ as an offline complexation reagent; (2) electrochemical oxidation of the complexed metal and thus formation of a radical cation (e.g.; $\mathrm{Fe}-\mathrm{e}^{-} \rightarrow \mathrm{Fe}^{++}$); (3) radical fragmentation of the complexed compound; (4) electrospray ionization of the fragmented neutrals. Fragmentation patterns resembling $b$ - and y-type ions were observed and allowed the localization of the phosphorylation sites. (J Am Soc Mass Spectrom 2010, 21, 2051-2061) (c) 2010 American Society for Mass Spectrometry
\end{abstract}

$\mathrm{S}$ ince its inception, fundamental studies have greatly improved our understanding of electrospray [1]. It is, for instance, now no longer questioned that the electrospray source also functions as an electrolytic cell, where electrochemical oxidations can happen as originally proven by Blades et al. [2] and extensively studied by van Berkel and Kertesz [3]. The focus of these studies was the reactions in the gas phase, and not those at the surface of the electrodes. It is thus not surprising that until recently, the connection between the electrolytic nature of electrospray and the onset of commonly observed discharges (i.e., the release of electrons) was not well understood. For instance, in a recent review, Kebarle et al. have associated the onset of these discharges with cosmic rays or background radiation. What we have recently shown is that the onset of the discharges is associated with the electrochemistry that Kebarle initially described [1,2]. CD is initiated at the sharp edge of the capillary due to its high potential energy and follows the normal voltage-current characteristics as established by Penning, where dependent on the current, discharges are classified as dark discharges $\left(10^{-10} \mathrm{~A}-10^{-5} \mathrm{~A}\right)$, glow discharges $\left(10^{-5} \mathrm{~A}-\right.$ ca $\left.1 \mathrm{~A}\right)$ and arc discharges (ca $\left.1 \mathrm{~A}-10^{4} \mathrm{~A}\right)[4-6]$. At dark discharges, very few electrons $\left(10^{-10} \mathrm{~A}-10^{-5} \mathrm{~A}\right)$ are released, light

Address reprint requests to Dr. S. Hess, California Institute of Technology, BI 211, MC139-74, Pasadena, CA 91125, USA. E-mail: shess@caltech.edu emission is thus negligible. In contrast, corona discharge $(C D)$ is characterized by a stable emission of blue or red light, depending on the electron densities of the plasma. CD is a special case in that it oscillates at steady-state between the Townsend region of the dark discharge and the glow discharge region, roughly between $10^{-7} \mathrm{~A}-10^{-4} \mathrm{~A}$. These oscillations are very well studied, experimentally by Trichel, hence the name Trichel pulses, and theoretically by Morrow $[7,8]$. In addition, the flow of electrons out of the electrospray tip measured in ESI and CD-ESI techniques has been extensively studied and documented [6,9]. We have recently shown that corona discharge $(C D)$ can be used as an effective method to create a radical cation species $[\mathrm{M}]^{+*}$ using a regular ESI source and appropriate MS settings [6]. To achieve a stable $C D$, the exit tip of a stainless steel electrospray capillary was extended 3 $\mathrm{mm}$ beyond the desolvation gas tube, the nitrogen gas temperature was raised to at least $500{ }^{\circ} \mathrm{C}$, and the ES high voltage to at least $5 \mathrm{KV}$. As shown in Figure 1, the ion plasma created was diverted away from the ESI spray path by a ground electrode placed behind the ESI capillary exit. CD at the capillary tip oxidizes the Fe in the stainless steel, which subsequently oxidizes redox active analytes when the ionization potential of the analyte is equal to or lower than that of Fe. Detection of $\mathrm{N}$-ferrocenyl iodoacetamide (FCIAA) at the low zeptomolar level was demonstrated. The excellent sensitivity 


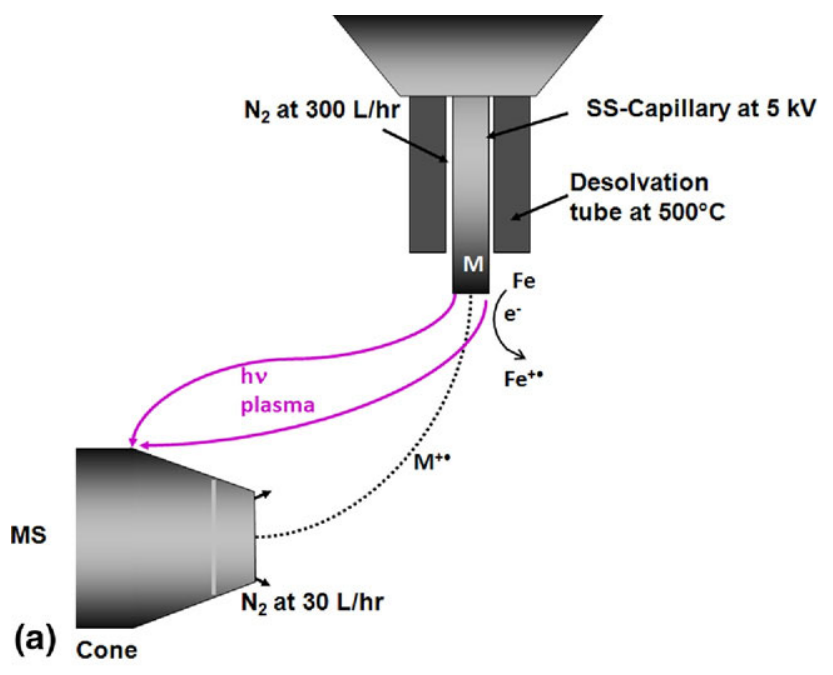

(b)

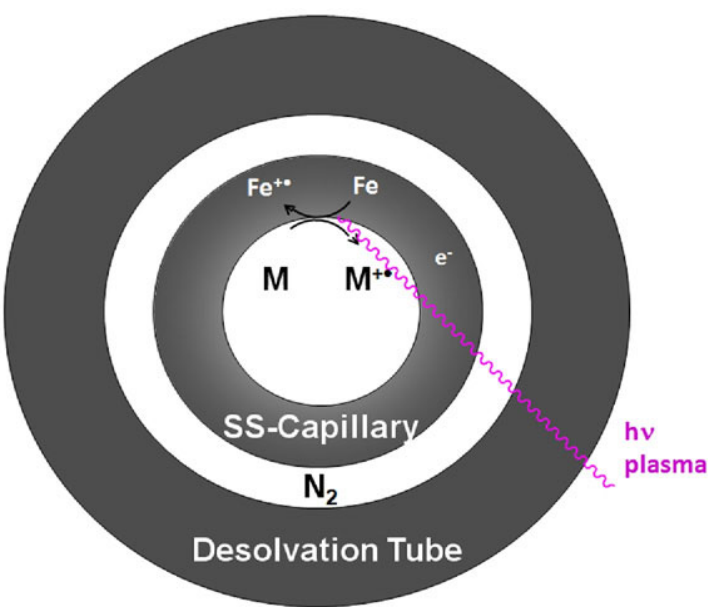

Figure 1. Experimental setup shown in (a) side view: in CD-ECI, the plasma ion path was directed away from the analyte ion path to the ground plate behind the orifice. CD removed an electron from Fe at the sharp edge of the SS capillary resulting in radical $\mathrm{Fe}^{+\cdot}$. Analytes (M) with ionization potential lower than $\mathrm{Fe} / \mathrm{Fe}^{+}$ were ionized by electrochemical oxidation and fragmented. During this process, $\mathrm{Fe}^{0}$ was regenerated. The surface interaction is critical for the formation of the radical ions and for their subsequent fragmentation; (b) top view: right after the generation of the analyte and plasma, both paths are separated.

could be attributed to effective electrochemical ionization and the ability of the enolate form of FcIAA to bind and accumulate to the Fe in SS capillary [6]. We termed this process $\mathrm{CD}$ initiated electrochemical ionization (CD-ECI) [6]. The insight that electrochemical reactions at both electrodes are essential for the formation of CD was already recognized by Perrot in 1861 [10] and was summarized in the benchmarking book of Thomson, who also pointed out the similarities between current conducting gases and liquid electrolytes [11]. Surprisingly, the underlying surface chemistry was not intensively studied in either the engineering field or mass spectrometry until recently $[6,12]$.

Inspired by recent studies that used electrochemistry to generate radical ions to fragment peptides, we tested whether CD-ECI could be used in this regard [13-15].
Permentier and Bruins used an electrochemical flow cell coupled to a mass spectrometer to generate radicals that resulted in the specific cleavage of proteins at tyrosine and tryptophans [13]. Prudent and Girault used $\mathrm{Cu}(\mathrm{II})$ either in solution or a sacrificial $\mathrm{Cu}(0)$ anode to generate $\mathrm{Cu}$-peptide complexes that would then undergo an electrochemical redox reactions. Depending on the formed complex, some fragmented without collision induced dissociation (CID) while others required CID [14]. CID was also required for generating and fragmenting the peptide radical cations from $\mathrm{Cu}$ (auxiliary ligand)-peptide complexes investigated by other groups [16-20]. Using a different concept, namely a $\mathrm{CD}$ needle placed in a flow reactor between the capillary and the MS ion entrance, Vilkov et al. recently introduced a novel dissociation technique. Electrochemically generated $\mathrm{OH}$ radicals from the $\mathrm{CD}$ needle fragmented peptides through ion/molecule reactions. Here, the peptides were sprayed directly at the CD needle (conceptually similar to an APCI setup) resulting in a mixture of diagnostically useful c-, b-, and y-ions [15]. Other groups relied on generation of radical ions through homolytic cleavage to effectively fragment peptides by either free radical initiated peptides sequencing (FRIPS) using an N-terminal Vazo 68 conjugate as pioneered by Beauchamp et al. [21], or sidechain lysine peroxycarbamates as developed by Porter et al. [22]. In both cases, CID was necessary to generate and fragment the peptide radical ion species.

Here, we report on the fundamental studies using CD-ECI to induce analytically useful in-source fragmentation of a range of molecules including glycopeptides, enolate forming phenylglycine containing peptides, nucleosides, and phosphopeptides, and study the involved mechanism. Unlike other in-source fragmentation techniques that are generally described to be non-selective [15, 23], CD-ECI showed selectivity for enolate-forming, metal complexing compounds. Experiments were performed using CD-ECI techniques on an LCT time-of-flight (TOF) instrument. Comparisons were done with ESI techniques on an LCT or, in select cases, on a hybrid QTOF II instrument.

\section{Experimental}

\section{Materials}

All reagents were of the highest purity available. BOCL- $\alpha$-phenyl glycine $99 \%$, DMSO $\geq 99.9 \%$, PPPPPPPPPPPPPPR (P14R), calcineurin substrate phosphopeptide DLDVPIPGRFDRRVPSVAAE $97 \%$, pyridine $\geq 99 \%$, ristomycin A, HPLC grade acetonitrile, and formic acid were all obtained from Sigma-Aldrich, St. Louis, MO, USA. ${ }^{4 \mathrm{~F}} \mathrm{UP} 14 \mathrm{R}(\geq 95 \%)$, where ${ }^{4 \mathrm{~F}} \mathrm{U}$ was a 4 -fluorophenyl glycine, was from Anaspec, Freemont, CA, USA. The HPLC water was obtained from Riedel-deHaen (SigmaAldrich). The MassPREP Enolase Digest with Phosphopeptide Mix was purchased from Waters, Milford, MA. 


\section{LC Instrumentation}

A $1525 \mu$ binary HPLC (Waters) was used. Samples (2 $\mu \mathrm{L}$ ) were injected using a 2777 Sample Manager (Waters). A Zorbax-SB C3 $2.1 \times 150 \mathrm{~mm}, 5 \mu \mathrm{m}$ particle size was used at a flow rate of $200 \mu \mathrm{L} / \mathrm{min}$. Solvent A was $0.2 \%$ formic acid, $2 \%$ acetonitrile in water, and Solvent B was $0.2 \%$ formic acid, $2 \%$ water in acetonitrile.

\section{MS Instrumentation and ESI and CD-ECI Techniques}

Experiments were done with a Waters LCT Premier High Resolution TOF mass spectrometer equipped with the API Z-spray ESI ionization source or where specifically noted with a Waters QTOF II mass spectrometer (Waters). The LCT was operated in $\mathrm{W}$-mode with a nominal resolution of $10 \mathrm{~K}$. The ionization mode was positive.

For ESI experiments the capillary voltage was $2 \mathrm{KV}$, the cone voltage was $30 \mathrm{~V}$, and the desolvation gas was nitrogen at a flow rate of $300 \mathrm{~L} / \mathrm{h}$ at $300{ }^{\circ} \mathrm{C}$. The angle of the stainless steel capillary to the ion entrance of the MS was $80^{\circ}$. The tip of the capillary was extended $0.5 \mathrm{~mm}$ from the desolvation tube. The source temperature was $125^{\circ} \mathrm{C}$.

Instrument parameters for CD-ECI mass spectrometry and liquid chromatography were used as previously described [6]: briefly, the capillary voltage was $5 \mathrm{KV}$, the cone voltage was $30 \mathrm{~V}$, and the desolvation gas was nitrogen at a flow rate of $300 \mathrm{~L} / \mathrm{h}$ at $500^{\circ} \mathrm{C}$. The angle of the stainless steel capillary to the ion entrance of the MS was $90^{\circ}$. The tip of the capillary was extended $3 \mathrm{~mm}$ from the desolvation tube. The source temperature was $125^{\circ} \mathrm{C}$.

For the QTOF experiment using UP14R, a Waters QTOF II was operated in positive ion mode with a nominal resolution of $5 \mathrm{~K}$. The ESI capillary voltage was $3.5 \mathrm{KV}$ and the cone voltage was $20 \mathrm{~V}$. The desolvation gas was nitrogen at a flow of $300 \mathrm{~L} / \mathrm{h}$ and a temperature of $250{ }^{\circ} \mathrm{C}$. The collision gas was nitrogen and the collision energy was $30 \mathrm{~V}$.

Additional information for the individual MS experiments is available in the Supplementary data, which can be found in the electronic version of this article.

\section{Results and Discussion}

For CD-ECI to occur, we have previously determined that the interaction of the analytes with the Fe in the SS electrode is essential. Inhibition of this interaction led to a dramatic loss in sensitivity and replacement of the SS capillary with a Ni capillary led to a total loss in signal [6]. At the same time, a thorough understanding of these interactions can also be used to analytical advantage. For instance, we have recently shown that the sulfated mutremdamide A can be analyzed by CD-ECI, but binds so tightly to the SS capillary that ESI only detected the hydrolyzed compound [24].

Depending on the nature of the surface interaction between the analyte and the SS, the electrochemically generated radicals can selectively induce fragmentation in a range of molecules, including glycopeptides, enolate forming phenylglycine containing peptides, phosphopeptides, and nucleosides that have been investigated in this study.

A most illustrative example of electrochemicallyinduced fragmentation using CD-ECI technique is the study of ristomycin A 1 . Figure 2 compares the chro-
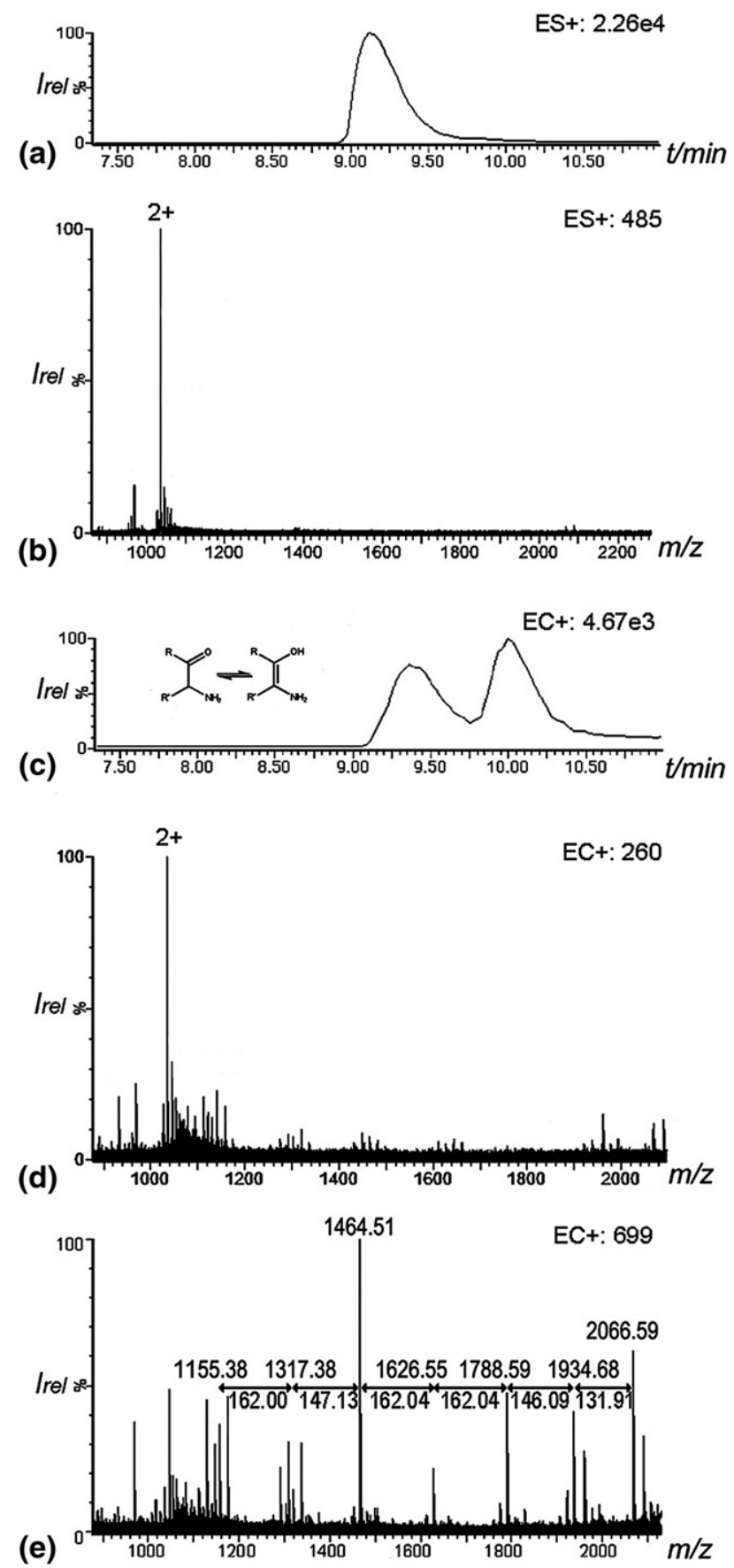

Figure 2. Chromatogram and spectra of ristomycin A 1 using ESI and CD-ECI technique. (a) ESI chromatogram of 1, and (b) ESI spectrum of 1 showing the expected doubly charged ions at $\mathrm{m} / \mathrm{z}=$ 1034.39. (c) CD-ECI chromatogram of 1 showing two coeluting peaks; (d) spectrum of the first peak of $\mathbf{1}$ in CD-ECI, and (e) spectrum of the second peak of 1 in CD-ECI (all in TOF mode). 
matograms and spectra of the glycopeptide 1 under ESI (Figure $2 \mathrm{a}, \mathrm{b}$ ) and CD-ECI (Figure $2 \mathrm{c}-\mathrm{e}$ ) technique. As expected, glycopeptide 1 eluted as one peak using ESI (Figure 2a). The corresponding ESI spectrum showed a predominantly doubly charged ion at $\mathrm{m} / \mathrm{z}=1034.39$ (Figure 2b). In contrast, when investigated by CD-ECI, two LC peaks appeared in the chromatogram (Figure $2 c$ ) with differing mass spectra (Figure $2 d$, e). While the spectrum corresponding to the first peak (Figure 2d) showed similarities to the ESI spectrum, the spectrum corresponding to the second peak (Figure 2e) showed intense fragmentation representing the subsequent loss of the sugar moieties in $\mathbf{1}$ (Scheme $\mathbf{1}$ ). We propose that this differing behavior is intrinsically related to the involved mechanisms in ESI and CD-ECI. We have previously shown the importance of the surface chemistry of the SS capillary in CD-ECI [6, 24]. Glycopeptide 1 exists in equilibrium of keto- and enol-tautomers (Figure 2c inset). While the keto tautomer cannot be complexed by the Fe in the SS capillary, the enol tautomer can be complexed and, due to this online complexation, can be retained slightly longer on the SS tip than the keto form, leading to two co-eluting peaks in CD-ECI. Using ESI this phenomenon will not be observed, since it has previously been shown that compounds that are capable to chelate $\mathrm{Fe}$ (as is the case for the enolate, but not the keto form of ristomycin) are not detectable due to complexation when a SS capillary was used [25-27]. Therefore, the detection of the Fe-enol complex of 1 would not be expected in ESI, and indeed, only the earlier eluting keto form of $\mathbf{1}$ was detected, but

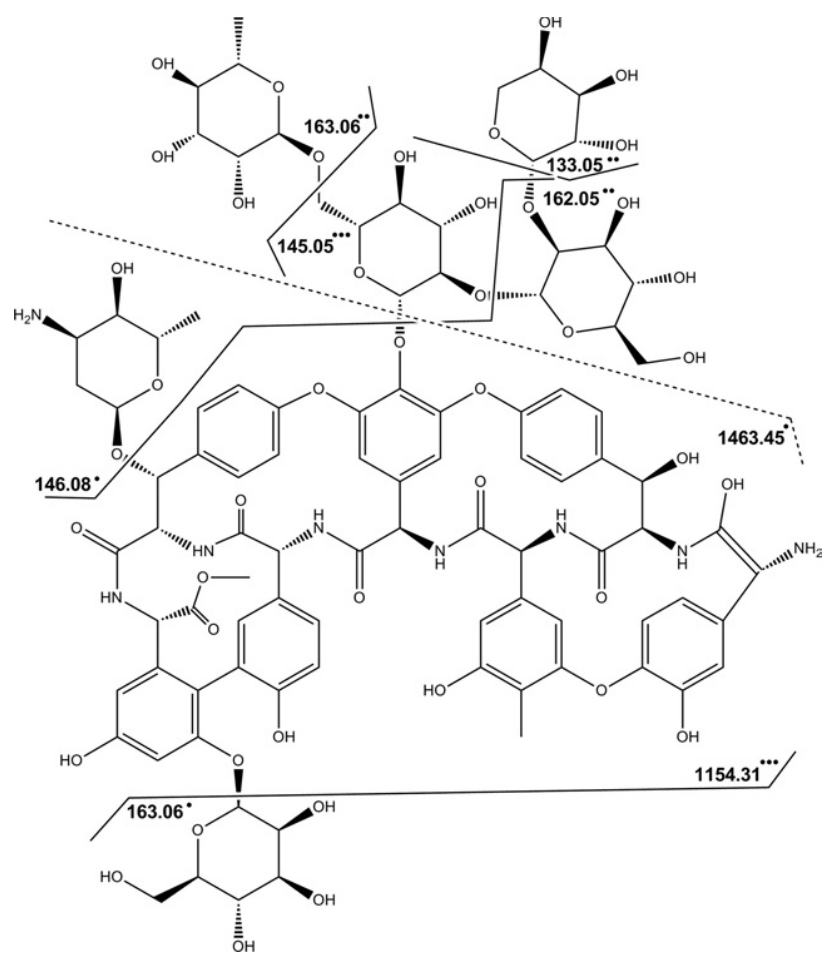

Scheme 1. Ristomycin A $\mathbf{1}$ and observed fragment assignments.
CD-ECI was able to detect both, the unfragmented keto (Figure 2d) and the fragmented enol (Figure 2e) tautomer of ristomycin. We propose this was enabled through the intrinsic CD-ECI mechanism: after complexation of the enol form with the $\mathrm{Fe}$ in the stainless steel capillary, the Fe can undergo oxidation via the CD-ECI process to form a radical cation organometallic moiety. This complexation with SS capillary is not unique and has previously been reported for phosphates [25-28]. In fact, it is the main reason why many proteomics researchers avoid SS capillary materials. After formation by CD-ECI, the radical cation can undergo free radical type fragmentation as evidenced by the type of fragmentation shown in Figure 2e. These radical fragments were no longer complexed by Fe and are thus released and detected by mass spectrometry. As can be seen in Figure 2e and Scheme 1, the observed product ions correspond to radically generated fragments of $\mathbf{1}$. In addition, the normal ESI process ionized neutral fragments, so fragmentation and ionization are two distinct processes.

When we complexed the enol form of $\mathbf{1}$ with $\mathrm{Na}^{+}$ instead of the Fe of the SS by adding NaI to the solution before the CD-ECI experiment, the described fragmentation did not occur, indicating that the complexation of Fe with the enol of $\mathbf{1}$ is necessary for both, radical ionization and fragmentation. In these experiments, the keto-enol equilibrium was shifted from the keto to the enol tautomer and then, while complexed with $\mathrm{Na}^{+}$, only one LC peak was observed corresponding to $[\mathrm{M}+$ $\mathrm{Na}^{+}$(data not shown). In contrast to transition metals like Fe in $\mathrm{SS}, \mathrm{Na}^{+}$would not be able to induce radical ionization and fragmentation since $\mathrm{Na}^{+}$has a $2 p$ [6] outer electron shell is stable and highly unlikely to have another electron removed. This is also reflected in the high IP for the second removal of an electron from $\mathrm{Na}^{+} / \mathrm{Na}^{2+}(47.2 \mathrm{eV})$.

To further investigate the fragmentation mechanism, a number of experiments were designed using phosphates, nucleotides, and phenylglycine containing peptides that can either complex transition metals and fragment or, alternatively, cannot complex transition metals and thus cannot fragment using CD-ECI technique.

Phosphate containing compounds have previously been described to form complexes with Fe [25-28] and thus, Fe-complexed phosphopeptides should fragment using CD-ECI technique, but not using ESI technique. A standard phosphopeptide DLDVPIPGRFDRRVpSVAAE 2 was used and investigated by infusion ESI and CD-ECI. As expected, Figure 3a shows the doubly, triply, and quadruply charged ions using ESI technique at $\mathrm{m} / \mathrm{z}$ 1097.02, 731.34, and 549.01, respectively. In contrast, Figure $3 \mathrm{~b}$ and $\mathrm{c}$ show additional fragmentation in CD-ECI technique not observed in ESI technique. This includes a series of $\mathrm{b}$ - and $\mathrm{y}$-like ions listed in Table $\mathrm{S} 1$ and $[\mathrm{M}+\mathrm{H}]^{+},\left[\mathrm{M}+\mathrm{H}-\mathrm{H}_{2} \mathrm{O}\right]^{+},\left[\mathrm{M}+\mathrm{H}-\mathrm{HPO}_{3}\right]^{+}$, $\left[\mathrm{M}+\mathrm{H}-\mathrm{H}_{3} \mathrm{PO}_{4}\right]^{+}$(Figure $3 \mathrm{~b}$ inset). Selected fragments in the $\mathrm{m} / \mathrm{z}$ range from 540 to 700 are shown in 

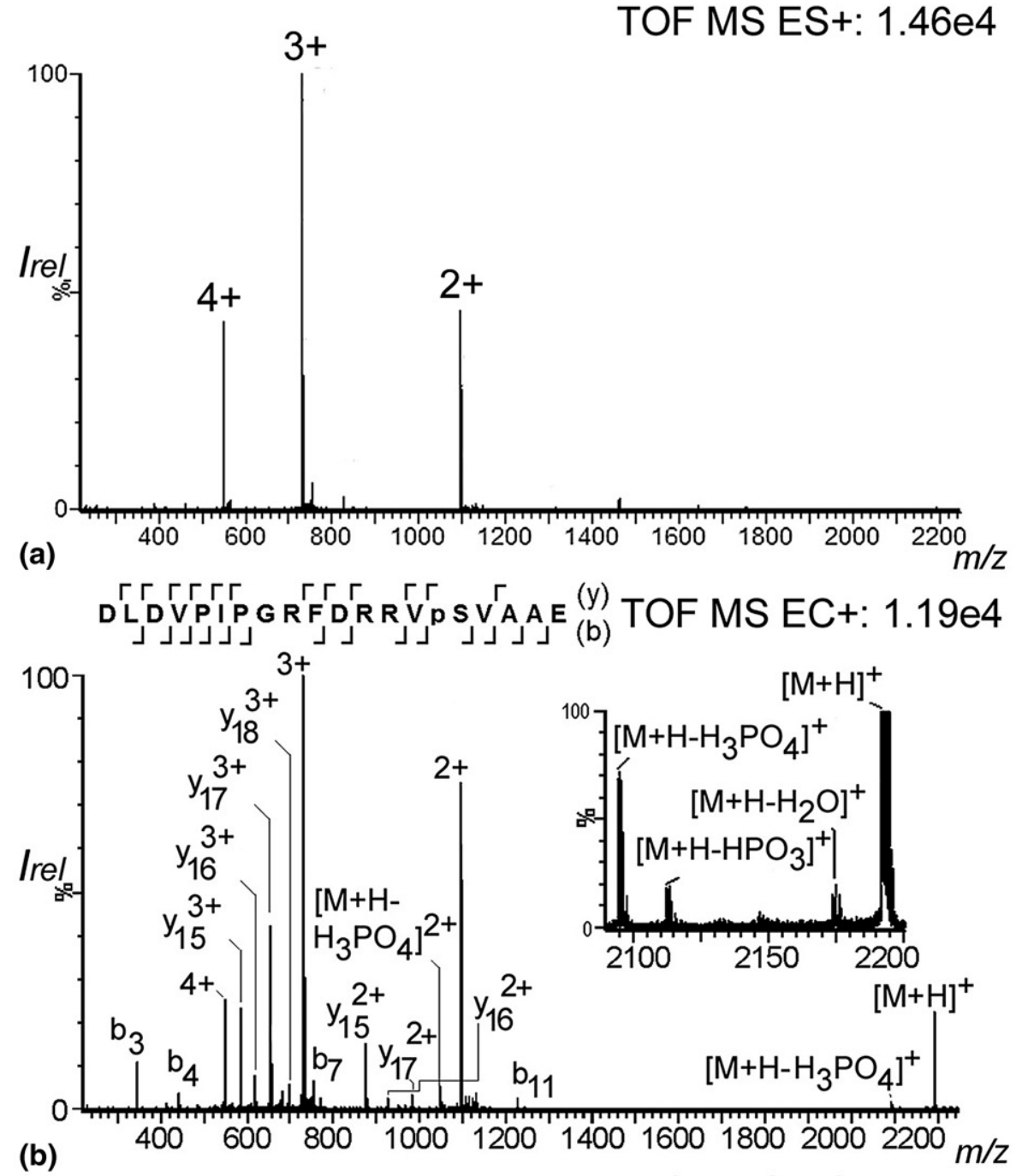

(b)

$4006008001000120014001600180020002200 \mathrm{~m} / \mathrm{z}$
TOF MS EC: $5.59 \mathrm{e} 3$

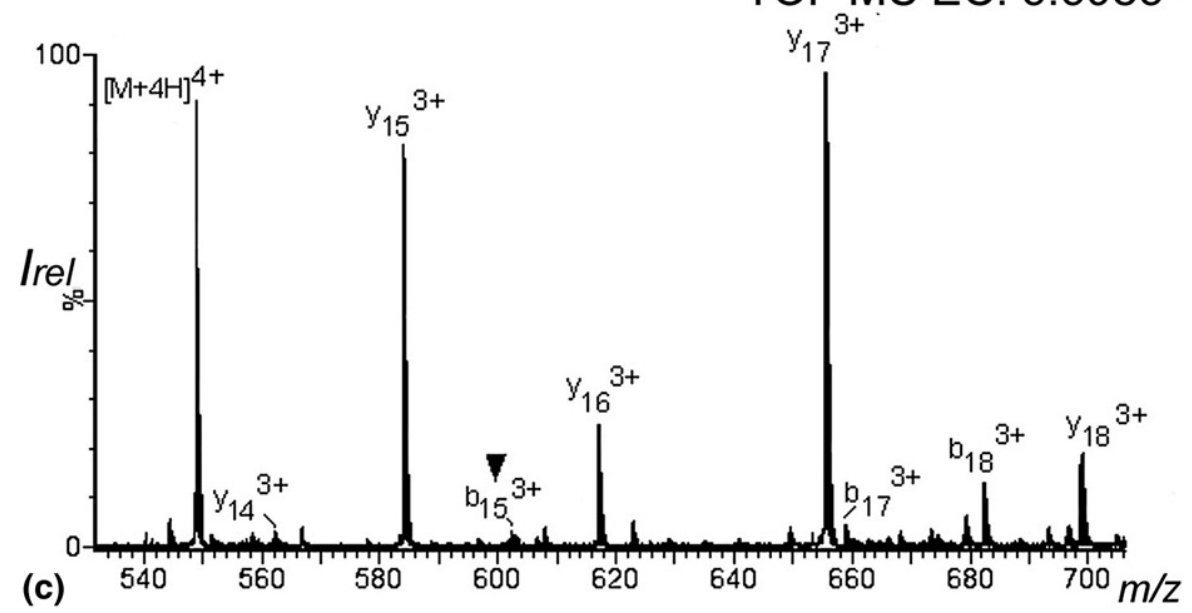

Figure 3. (a) ESI versus (b) CD-ECI spectrum of the phosphopeptide DLDVPIPGRFDRRVpSVAAE $2 \mathrm{in} \mathrm{TOF}$ MS mode. The inset shows the expanded mass range $m / z=2080-2200$ with the loss of $\mathrm{H}_{2} \mathrm{O}$, $\mathrm{HPO}_{3}$, and $\mathrm{H}_{3} \mathrm{PO}_{4}$; (c) expanded mass range 540-700 of CD-ECI spectrum of 2 indicating the phosphorylation site at $\mathrm{b}_{15}{ }^{3+}$ (inverted filled triangle).

Figure 3c. The observed fragmentation $\left(\mathrm{b}_{15}{ }^{2+/ 3+/ 4+}\right.$ and $\mathrm{y}_{5}{ }^{1+}$; Table S1) allowed the unequivocal determination of the position of the phosphorylation site of 2 . This experiment showed that a direct infusion of phosphopeptides under CD-ECI could indeed fragment the peptide and, due to sufficient preservation of labile 
phosphate groups, identify the phosphorylation site in a single TOF instrument.

The effect of exposure time to the SS capillary was investigated by lowering it to the timescale typical of an LC-MS experiment: A tryptically digested enolase spiked with phosphopeptides was separated on a C18 column and analyzed by CD-ECI. Figure 4 shows the chromatogram and the spectrum, respectively, of spiked phosphopeptide HLADLpSK 3 eluting at 7.48 min. The spectrum is characterized by backbone fragments of $b_{2}, b_{3}, b_{4}, b_{5}, y_{2}$ (indicating the site of phosphorylation), $\mathrm{y}_{5}, \mathrm{y}_{6}, \mathrm{a}_{2}$, and $\mathrm{z}_{7}$ ions. In addition, loss of $\mathrm{HPO}_{3}(-80)$ was observed for $\mathrm{y}_{7}, \mathrm{y}_{5}, \mathrm{y}_{4}, \mathrm{y}_{3}$, and $\mathrm{y}_{2}$. This experiment showed that indeed the complexation of phosphopeptides with Fe during LC is fast enough to allow specific fragmentation of phosphopeptides using CD-ECI technique. Somewhat similar to the $\mathrm{MS}^{\mathrm{E}}$ approach [29, 30], where MS data are simultaneously collected using high and low collision energies, a coeluting peak corresponding to IATAIEK did not interfere with the phosphopeptide assignment. In addition, there are already advanced software tools freely available that have been developed to evaluate concurrently fragmented peptides, allowing the analysis of more complicated mixtures [31].

While the example phosphopeptides shown here fragmented, there is a practical limitation to CD-ECI in that it requires the compound of interest to first bind to the SS capillary. This clearly excludes many compounds unless specific derivatizing reagents capable of causing diagnostic fragmentation of the desired compound are used that could circumvent the requirement for binding to the SS as a first step.

Towards this goal, we tested whether the addition of $\mathrm{Cu}$ (II) could function as such a derivatizing agent. Redox reactions of $\mathrm{Cu}$ complexes have previously been extensively studied in the gas phase [14, 16-20, 32-38]. It has previously been described that $\mathrm{Cu}$ (II) can be used to create molecular radical cations when electrosprayed as $\mathrm{Cu}(\mathrm{II})$-amine complex. These cations were described to be different from those generated by ECD and metal-bearing peptide ternary complexes [18]. It was also shown that $\mathrm{Cu}$ can induce fragmentation [14]. $\mathrm{Cu}(\mathrm{II})$ was therefore added to adenosine congener 4 and analyzed by ESI and CD-ECI. When investigated by ESI, the nucleoside adenosine congener $4\left(\mathrm{C}_{28} \mathrm{H}_{32} \mathrm{~N}_{8} \mathrm{O}_{6}\right.$;
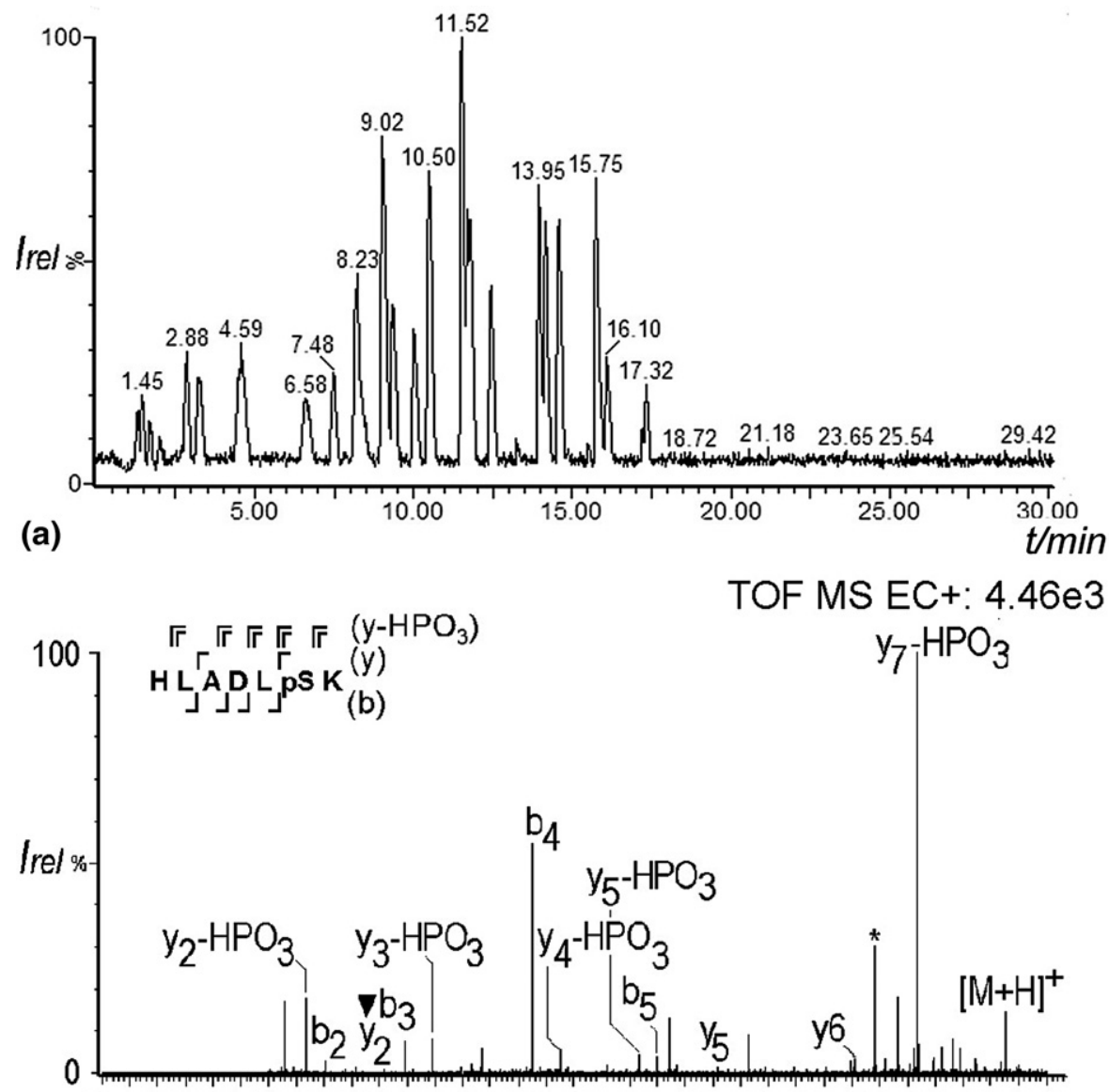

(b) $50100150200250300350400450500550600650700750800850900 \mathrm{~m} / \mathrm{z}$

Figure 4. (a) LC-chromatogram of enolase spiked with phosphopeptide HLADLpSK 3. (b) CD-ECI spectrum of the LC-separated 3 in TOF MS mode. * Denotes a co-eluting peak corresponding to IATAIEK peptide; (inverted filled triangle) denotes the phosphorylated fragment ion at $\mathrm{y}_{2}$. 
$\mathrm{M}_{\mathrm{R}}=576.6 \mathrm{Da}$ ) gave the spectrum shown in Figure 5a, $\mathrm{b}$ (without $\mathrm{Cu}(\mathrm{II})$ and with $\mathrm{Cu}(\mathrm{II})$ ). In ESI, essentially no fragment ions were observed, and 4 gave $[\mathrm{M}+\mathrm{H}]^{+}$, $[\mathrm{M}+2 \mathrm{H}]^{2+},[\mathrm{M}+\mathrm{K}]^{+},[\mathrm{M}+\mathrm{Na}]^{+}$ions.

In contrast, when investigated by CD-ECI, Fe or $\mathrm{Cu}$ (II)-chelated adenosine congener 4 showed diagnostically useful fragmentation with $\mathrm{Cu}$ (II) treatment leading to both, more intense total ion chromatograms (TICs) and fragmentation (Figure 5c, d and Supplementary Figure S1). Next to intact 4 represented by [M + $\mathrm{H}]^{+},[\mathrm{M}+\mathrm{Na}]^{+},[\mathrm{M}+\mathrm{K}]^{+},[\mathrm{M}+2 \mathrm{H}]^{2+}$, fragmentation was observed with the main fragment $[\mathrm{M}+2 \mathrm{H}-\mathrm{Rib}]^{+}$. at $m / z=445.18$ Da. A $\Delta 28$ impurity that was not identified in ESI was identified at $\mathrm{m} / \mathrm{z}=473.20 \mathrm{Da}$ representing $[\mathrm{M}+\Delta 28+2 \mathrm{H}-\mathrm{Rib}]^{+\cdot}$ and at $\mathrm{m} / z=627.24$ Da representing $[\mathrm{M}+\Delta 28+\mathrm{Na}]^{+}$. In addition, fragments were observed for $[\mathrm{M}+2 \mathrm{H}-\mathrm{Rib}]^{2+},[\mathrm{M}+3 \mathrm{H}-$ $\left.\mathrm{Rib}-\mathrm{C}_{2} \mathrm{H}_{4} \mathrm{NH}_{2}\right]^{+*},\left[\mathrm{M}+\mathrm{H}-\mathrm{NH}_{2}\right]^{2+},[\mathrm{M}+2 \mathrm{H}-$ $\left.\mathrm{Rib}-\mathrm{NH}_{2}\right]^{2+}$ (Figure 5c, d).

What these experiments demonstrate is that chelation is necessary for fragmentation and that the fragmentation is the same regardless of whether 4 was chelated to the $\mathrm{Fe}$ in the SS (Figure $5 \mathrm{c}$ ) or to $\mathrm{Cu}(\mathrm{II})$ before MS (Figure 5d). The increased TIC and fragmentation also indicated that $\mathrm{Cu}$ (II) addition can be used to induce fragmentation in compounds capable of chelating $\mathrm{Cu}$. The obvious advantage of $\mathrm{Cu}$ (II) addition is that one can increase incubation times before CD-ECI analysis and thus analyze samples that would otherwise not be amenable to CD-ECI.

To test this further, we synthesized UP14R 5 and ${ }^{4 \mathrm{~F}} \mathrm{UP} 14 \mathrm{R} 6$ 6, where $\mathrm{U}$ is phenylglycine and ${ }^{4 \mathrm{~F}} \mathrm{U}$ is 4 fluorophenylglycine and compared it with the commonly used standard P14R 7, with and without prior $\mathrm{Cu}(\mathrm{II})$ treatment, both using ESI and CD-ECI. Phenylglycine and 4-fluorophenylglycine were specifically chosen because of their well-documented differences in exhibiting keto-enol tautomerism. Due to the electronegative fluorine in the para position, the $\alpha$-hydrogen in ${ }^{4 \mathrm{~F}} \mathrm{U}$ is easily abstracted and the created enol structure is resonance-stabilized and energetically favored (as shown in Figure S2) [39]. In contrast, phenylglycine preferentially exists in the keto form, but can be trapped in the enol form under suitable chemical conditions, such as formation of a copper complex. While oligoproline $\mathbf{7}$ is prone to dissociation in CID experiments [40], out of these 12 experiments, only those three experiments that favor enolate complexation showed fragmentation in CD-ECI: first, CD-ECI after $\mathrm{Cu}$ (II) treatment of 5, but not without prior $\mathrm{Cu}$ (II) treatment; second, CD-ECI of 6 with $\mathrm{Cu}(\mathrm{II})$ treatment; and third, CD-ECI of 6 without $\mathrm{Cu}(\mathrm{II})$ treatment. As expected from the mechanism that is dependent on the surface interaction of the enolate

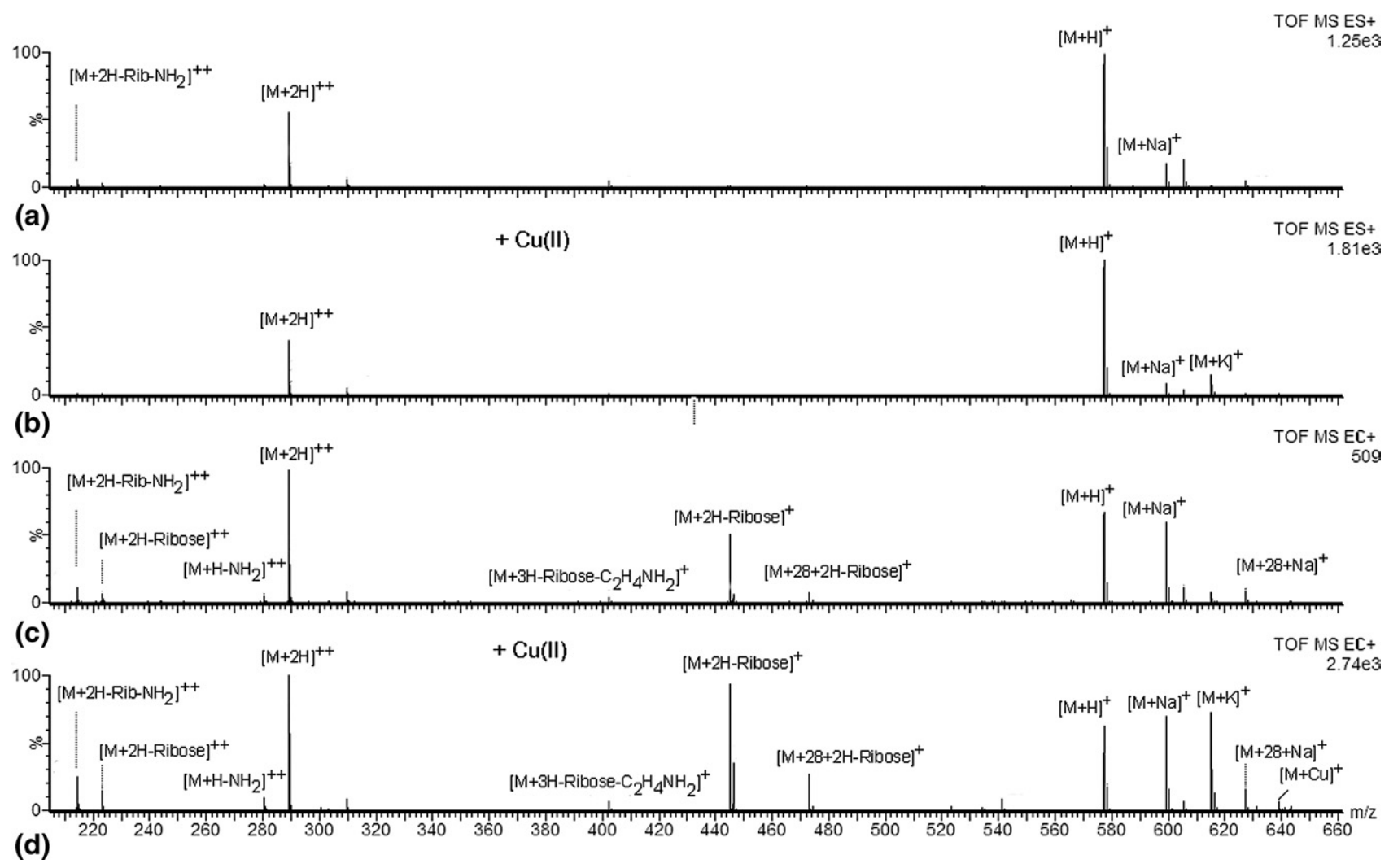

Figure 5. Adenosine congener 4 investigated by (a) ESI without $\mathrm{Cu}(\mathrm{II})$, (b) ESI with $\mathrm{Cu}(\mathrm{II})$, (c) $\mathrm{CD}$-ECI without $\mathrm{Cu}(\mathrm{II})$, and (d) $\mathrm{CD}$-ECI with $\mathrm{Cu}(\mathrm{II})$. Fragmentation was only observed in CD-ECI technique regardless whether $\mathrm{Cu}(\mathrm{II})$ was added or not, indicating that $\mathrm{Cu}(\mathrm{II})$ can be used as a reagent to replace Fe. 
with the SS, all other conditions did not fragment in either CD-ECI or ESI.

The deconvoluted spectrum of the fragmentation pattern observed for the $\mathrm{Cu}$ (II) chelated 5 using CD-ECI is shown in Figure 6a. Since no fragmentation was

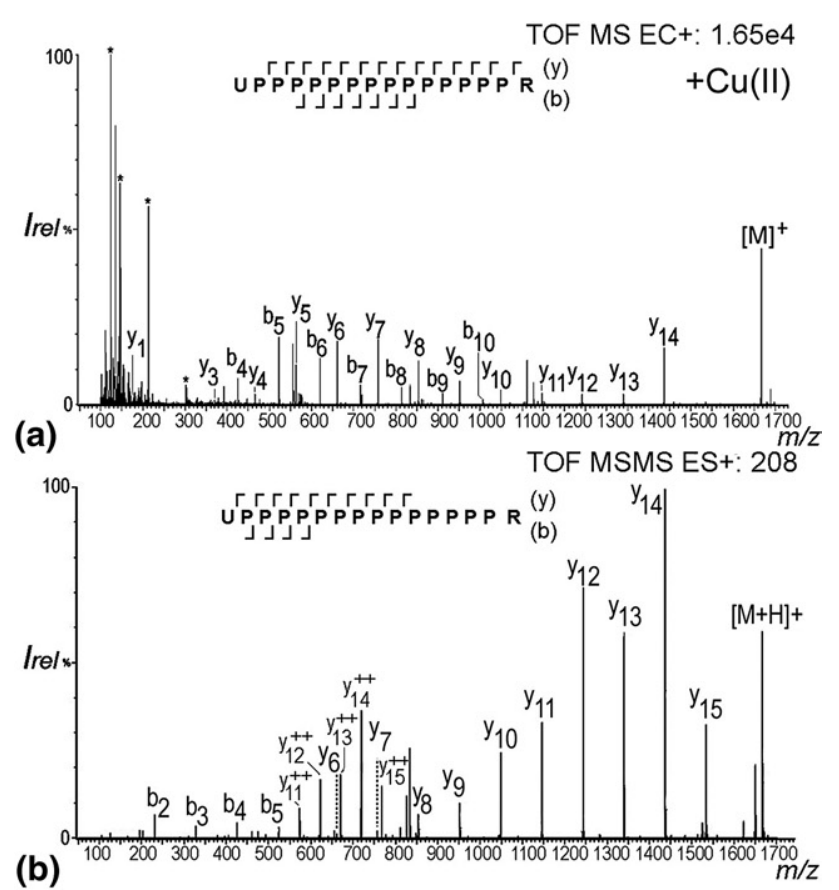

(b)

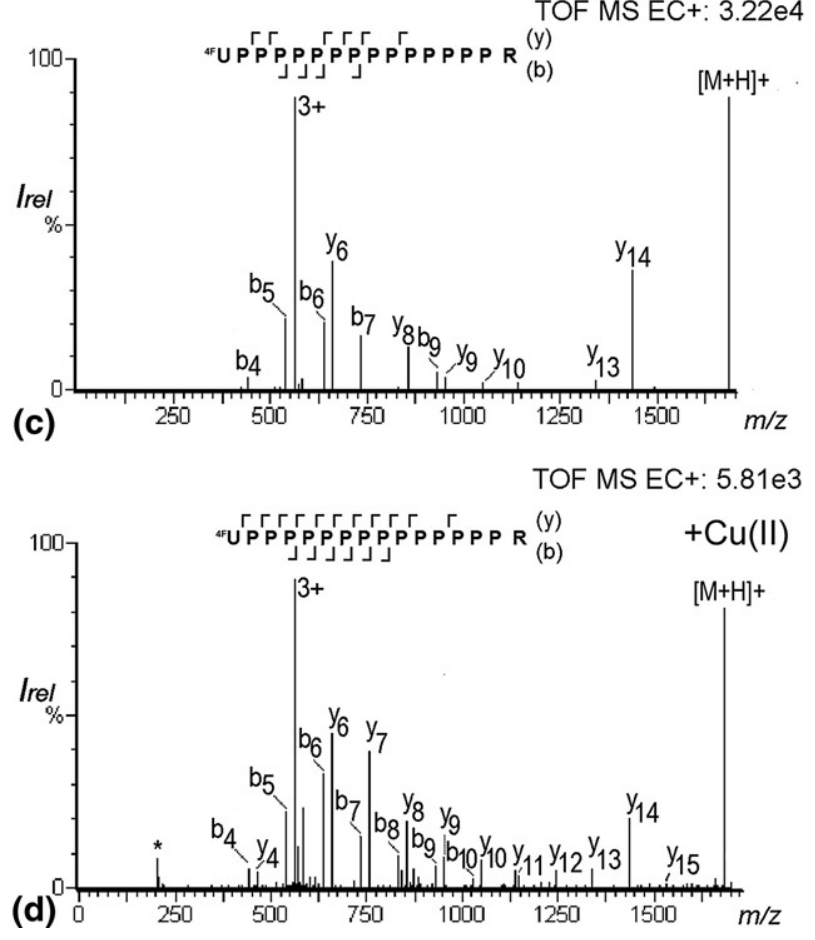

Figure 6. (a) CD-ECI spectrum of the $\mathrm{Cu}$ (II) complexed UP14R 5 measured in a single TOF LCT instrument $\left({ }^{*}\right.$ denotes common background ions); (b) collision-induced dissociation spectrum of 5 measured in QTOF instrument; (c) CD-ECI spectrum of 4FUP14R 6 measured in a single TOF LCT instrument without $\mathrm{Cu}(\mathrm{II})$ addition; (d) CD-ECI spectrum of the $\mathrm{Cu}$ (II) complexed 4FUP14R 6 measured in a single TOF LCT instrument. observed without prior $\mathrm{Cu}(\mathrm{II})$ treatment using $\mathrm{CD}$-ECI technique, this experiment confirmed that prior $\mathrm{Cu}$ (II) treatment could be used to complex enolates that did not react with Fe in the SS tip and thus extend the scope of compounds that can be fragmented by CD-ECI. This was further corroborated by the fact that the enolate stabilized 6 showed fragmentation with or without prior $\mathrm{Cu}(\mathrm{II})$ treatment, although the fragmentation without $\mathrm{Cu}$ (II) treatment was less pronounced than with $\mathrm{Cu}(\mathrm{II})$ treatment. While we have considered alternatives, the only explanation for the difference in the requirement of prior $\mathrm{Cu}(\mathrm{II})$ treatment for the phenylglycine derivative 5 and the 4-fluorophenylglycine derivative 6 to be effectively fragmented when using CD-ECI is that the equilibrium of the keto-enol tautomers lies at the site of the enolate in $\mathbf{6}$ and at the site of the keto form in $\mathbf{5}$. Only, when the enolate in $\mathbf{5}$ is trapped with $\mathrm{Cu}$, fragmentation is observed, while $\mathbf{6}$ is stabilized in the enolate form regardless of the presence of $\mathrm{Cu}$. These experiments strongly supported the hypothesis that enolate formation and complexation with a transitionmetal must be essential for the fragmentation mechanism since compounds lacking this structural feature (e.g., 7) could not be fragmented at all in CD-ECI. Only in conventional ESI-CID was fragmentation of $7 \mathrm{ob}-$ served (data not shown).

As shown in Figure 6a, the CD-ECI fragmentation of 5 in a TOF instrument is remarkably similar to the fragmentation that is observed under ESI-CID using a quadrupole time of flight (QTOF) instrument (Figure $6 b)$. A continuous $y$-ion series $\left(\mathrm{y}_{3}-\mathrm{y}_{14}\right)$ and, interestingly, very intense $b$-ion series $\left(b_{4}-b_{10}\right)$ characterized the CD-ECI spectrum (Figure 6a). Also $\mathrm{a}_{1}, \mathrm{y}_{1}, \mathrm{z}_{1}$, and $\mathrm{z}_{2}$ were observed. As expected, no fragmentation was observed in ESI (data not shown). The ESI-QTOF MS/MS CID spectrum of $\mathbf{5}$ showed a y-ion series from $\mathrm{y}_{6}-\mathrm{y}_{15}$ and very low abundant $\mathrm{b}_{2}-\mathrm{b}_{5}$ (Figure $6 \mathrm{~b}$ ). In addition to the singly charged y-ions, not fully deconvoluted doubly charged ions $\left(\mathrm{y}_{9}{ }^{2+}-\mathrm{y}_{15}{ }^{2+}\right)$ and the QTOF typical $\mathrm{a}_{2}$ and, additionally, $\mathrm{a}_{5}$ were observed.

From a comparison of the CD-ECI spectra of the 4-fluorophenyglycine containing 6 without (Figure 6c) and with $\mathrm{Cu}$ (II) treatment (Figure 6d), it is apparent that 6 also fragmented without prior $\mathrm{Cu}$ (II) treatment and that the fragmentation is overall similar, albeit prior $\mathrm{Cu}$ (II) treatment increased the fragmentation due to enhanced enolate trapping. Similar to studies by Lebrilla et al. using P14R 7 with infrared multiphoton dissociation (IRMPD), sustained off-resonance irradiation collision-induced dissociation (SORI-CID), and infrared and collisional activation (CIRCA), where no $\mathrm{b}$-ions were found, CID produced only minor signals for $b_{2}-b_{5}$ [41]. The strong signal for the $b$-ions in CD-ECI is thus unique to this technique, indicating that its fragmentation is by far less dependent on the position of the basic residue than IRMPD, SORI-CID, and CIRCA. Overall, the CD-ECI spectra of 5 and $\mathbf{6}$ showed rich fragmentation with diagnostically useful fragments in simple TOF spectra without activation. 
In this study, we mainly observed b- and y-type ions as they would normally be expected during collisioninduced dissociation according to the mobile proton theory [42, 43] and not necessarily in odd-electron driven pathways, although depending on the charge carrier and peptides structure, b-ion formation has also been reported for electron capture dissociation (ECD) [36, 44-48]. The previously described electron driven pathways [e.g., for electron capture dissociation (ECD) or electron-transfer dissociation (ETD)] were generated by the addition of an electron (reduction) as described in eq 1.

$$
[\mathrm{M}+\mathrm{nH}]^{n+}+\mathrm{e}^{-} \rightarrow\left[[\mathrm{M}+\mathrm{nH}]^{(\mathrm{n}-1)+}\right]
$$

This is fundamentally different to CD-ECI, where ions were generated by the removal of an electron (oxidation) as shown in eqs 2 and 3. While the analyte is oxidized to $[\mathrm{M}]^{++}, \mathrm{Fe}^{+\cdot}$ is reduced to $\mathrm{Fe}$, so that a new oxidation can be initiated.

$$
\begin{aligned}
& \mathrm{Fe}^{+\cdot}+\mathrm{e}^{-} \rightarrow \mathrm{Fe} \\
& {[\mathrm{M}]-\mathrm{e}^{-} \rightarrow[\mathrm{M}]^{+}}
\end{aligned}
$$

There is precedence for radical oxidation reactions using $\mathrm{Cu}$-complexes, where unusual radical-driven dissociation pathways including $b$ - and y-ion formation, have previously been described after CID [20, 34, 35], when bi- or tridentate ligands (L) such as 2,2"bipyridine and $2,2^{\prime}: 6^{\prime}, 2^{\prime \prime}$-terpyridine were part of the complex (eqs 4 and 5) [20, 34, 35].

$$
\begin{aligned}
& {\left[\mathrm{Cu}^{\mathrm{II}} \mathrm{LM}\right]^{2+} \rightarrow\left[\mathrm{Cu}^{\mathrm{I}} \mathrm{LM}-\mathrm{b}_{\mathrm{n}}\right]^{+}+\mathrm{b}_{\mathrm{n}}} \\
& {\left[\mathrm{Cu}{ }^{\mathrm{II} L M}\right]^{2+} \rightarrow\left[\mathrm{Cu}{ }^{\mathrm{I}} \mathrm{LM}-\mathrm{y}_{\mathrm{n}}\right]^{+}+\mathrm{y}_{\mathrm{n}} .}
\end{aligned}
$$

While the bi- and tridentate ligands used in these studies form very stable complexes that can be detected by MS, we obtained weaker complexes and, thus, $\mathrm{Cu}$ (II) dissociated and only $b$ - and y-ions were observed. This observation is in agreement with quantum chemical calculations for hypervalent nitrogen-protonated peptide radicals [49]. We thus propose that a Cu-complex was formed by reacting with the enolate of the peptide. The radical $\mathrm{Cu}(\mathrm{II})^{+\cdot}$ removes an electron from the peptide and thus initiates fragmentation into b- and y-type ions as indicated in eqs 6 and 7.

$$
\begin{gathered}
{\left[\mathrm{Cu}^{\mathrm{II} M}\right]^{2+}+\mathrm{H}_{2} \mathrm{O} \rightarrow \mathrm{Cu}{ }^{\mathrm{II}} \mathrm{O}+\left[\mathrm{M}-\mathrm{y}_{\mathrm{n}}\right]^{+\cdot}+\mathrm{b}_{\mathrm{n}}+\mathrm{H}_{2}} \\
{\left[\mathrm{Cu}^{\mathrm{II}} \mathrm{M}\right]^{2+}+\mathrm{H}_{2} \mathrm{O} \rightarrow \mathrm{Cu}^{\mathrm{II}} \mathrm{O}+\left[\mathrm{M}-\mathrm{b}_{\mathrm{n}}\right]^{+\cdot}+\mathrm{y}_{\mathrm{n}}+\mathrm{H}_{2}}
\end{gathered}
$$

As has been observed for photodissociation, the fragmentation of the electron-deficient species is more sim- ilar to CID even though no activation techniques were applied [50,51]. With a few exceptions, such as $z_{1}$ and $z_{2}$ in 5, fragment ions typical for ECD and ETD (c- and $z$-ions) were generally not observed. While we have initially considered ion-molecule reactions or electron impact ionization mechanism, the selectivity of the observed fragmentation exclude these mechanisms.

\section{Conclusions}

This study demonstrates that CD-ECI can be effectively used to fragment nucleosides, glycopeptides, and phosphopeptides into diagnostically useful ions in a single TOF instrument (without activation techniques). A four step mechanism was proposed: (1) complexation using either Fe in the SS capillary tip material or $\mathrm{Cu}(\mathrm{II})$ as an offline complexation reagent; (2) electrochemical oxidation of the complexed metal and thus formation of a radical cation (e.g., $\mathrm{Fe}-\mathrm{e}^{-} \rightarrow \mathrm{Fe}^{++}$); (3) radical induced fragmentation of the complexed compound; (4) electrospray ionization of the fragmented neutrals. Fragmentation patterns resembling $b$ - and y-type ions were observed. Like ECD or ETD techniques [52-56], the radical-driven fragmentation is softer than CID fragmentation. Therefore, phosphate groups were retained in fragment ions allowing the localization of the phosphorylation site. Unlike ECD or ETD, CD-ECI created an electron deficient species. The observed fragmentation is thus unique. Future investigation may be directed towards studies expanding the applications of the CD-ECI technique. The CD-ECI fragmentation platform is mechanically very simple and thus lends itself for miniaturization that can further increase achievable sensitivities [57]. In addition, it is our goal to determine the boundaries of the CD-ECI technique by exploring additional compound classes amenable to CD-ECI. Our current investigations focus on using CD-ECI to fragment proteins in a top-down like fashion.

\section{Acknowledgments}

This article is dedicated to Dr. Henry M. Fales, National Heart, Lung, and Blood Institute, National Institutes of Health. The authors acknowledge research support from the National Institute of Diabetes and Digestive and Kidney Diseases (Z01 DK07000404), the Beckman Institute, and the Gordon and Betty Moore Foundation is gratefully acknowledged. The authors thank WaiMing Yau for synthesizing peptide UP14R. They thank Anastasia Kalli and Robert Graham for critical review of the manuscript.

\section{Appendix A Supplementary Material}

Supplementary material associated with this article may be found in the online version at doi:10.1016/ j.jasms.2010.08.018. 


\section{References}

1. Kebarle, P.; Verkerk, U. H. Electrospray: From Ions in Solution to Ions in the Gas Phase, What We Know Now. Mass Spectrom. Rev. 2009, 28, 898-917.

2. Blades, A. T.; Ikonomou, M. G.; Kebarle, P. Mechanism of Electrospray Mass-Spectrometry-Electrospray as an Electrolysis Cell. Anal. Chem. 1991, 63, 2109-2114.

3. Van Berkel, G. J.; Kertesz, V. Using the Electrochemistry of the Electrospray Ion Source. Anal. Chem. 2007, 79, 5510-5520.

4. Druyvesteyn, M. J.; Penning, F. M. The Mechanism of Electrical Discharges in Gases of Low Pressure. Rev. Mod. Phys. 1940, 12, 0087-0174.

5. Baars-Hibbe, L. Characterization and Applications of High Frequency Discharges in the near-Atmospheric Pressure Range Using MicroStructured Electrode Arrays; Cuvillier Verlag: Goettingen, 2005; p. 163.

6. Lloyd, J. R.; Hess, S. A Corona Discharge Initiated Electrochemical Electrospray Ionization Technique. J. Am. Soc. Mass Spectrom. 2009, 20, 1988-1996.

7. Trichel, G. W. The Mechanism of the Positive Point-to-Plane Corona in Air at Atmospheric Pressure. Phys. Rev. 1939, 55, 0382-0390.

8. Morrow, R. The Theory of Positive Glow Corona. J. Phys. D Appl. Phys. 1997, 30, 3099-3114.

9. Marginean, I.; Kelly, R. T.; Prior, D. C.; LaMarche, B. L.; Tang, K.; Smith, R. D. Analytical Characterization of the Electrospray Ion Source in the Nanoflow Regime. Anal. Chem. 2008, 80, 6573-6579.

10. Perrot, A. Recherches Sur L'action Chimique De L'ectincelle D'induction De L'appareil Ruhmkorff. Annales de Chimie et de Physique. 1861, 61, 161-199.

11. Thomson, J. J. Notes on Recent Researches in Electricity and Magnetism, Intended as a Sequel to Professor Clerk-Maxwell's Treatise on Electricity and Magnetism. The Clarendon Press: Oxford, 1893; pp 177-207.

12. Goldman, M.; Goldman, A.; Sigmond, R. S. The Corona Discharge, Its Properties and Specific Uses. Pure Appl. Chem. 1985, 57, 1353-1362.

13. Permentier, H. P.; Bruins, A. P. Electrochemical Oxidation and Cleavage of Proteins with On-Line Mass Spectrometric Detection: Development of an Instrumental Alternative to Enzymatic Protein Digestion. J. Am. Soc. Mass Spectrom. 2004, 15, 1707-1716.

14. Prudent, M.; Girault, H. H. On-Line Electrogeneration of CopperPeptide Complexes in Microspray Mass Spectrometry. J. Am. Soc. Mass Spectrom. 2008, 19,560-568.

15. Vilkov, A. N.; Laiko, V. V.; Doroshenko, V. M. Peptide Fragmentation Induced by Radicals at Atmospheric Pressure. J. Mass Spectrom. 2009, 44, 477-484.

16. Barlow, C. K.; Wee, S.; McFadyen, W. D.; O'Hair, R. A. Designing Copper(II) Ternary Complexes to Generate Radical Cations of Peptides in the Gas Phase: Role of the Auxiliary Ligand. Dalton Trans. 2004, 20, 3199-3204.

17. Chu, I. K.; Lam, C. N. W.; Siu, S. O. Facile Generation of Tripeptide Radical Cations In Vacuo Via Intramolecular Electron Transfer in Cu-II Tripeptide Complexes Containing Sterically Encumbered Terpyridine Ligands. J. Am. Soc. Mass Spectrom. 2005, 16, 763-771.

18. Chu, I. K.; Rodriquez, C. F.; Lau, T. C.; Hopkinson, A. C.; Siu, K. W. M. Molecular Radical Cations of Oligopeptides. J. Phys. Chem. B 2000, 104, 3393-3397.

19. Chu, I. K.; Siu, S. O.; Lam, C. N. W.; Chan, J. C. Y.; Rodriquez, C. F. Formation of Molecular Radical Cations of Aliphatic Tripeptides from Their Complexes with Cu-II(12-Crown-4). Rapid Commun. Mass Spectrom. 2004, 18, 1798-1802.

20. Lam, C. N.; Ruan, E. D.; Ma, C. Y.; Chu, I. K. Non-Zwitterionic Structures of Aliphatic-Only Peptides Mediated the Formation and Dissociation of Gas Phase Radical Cations. J. Mass Spectrom. 2006, 41, 931-938.

21. Hodyss, R.; Cox, H. A.; Beauchamp, J. L. Bioconjugates for Tunable Peptide Fragmentation: Free Radical Initiated Peptide Sequencing (FRIPS). J. Am. Chem. Soc. 2005, 127, 12436-12437.

22. Masterson, D. S.; Yin, H. Y.; Chacon, A.; Hachey, D. L.; Norris, J. L.; Porter, N. A. Lysine Peroxycarbamates: Free Radical-Promoted Peptide Cleavage. J. Am. Chem. Soc. 2004, 126, 720-721.

23. Chapman, J. R. Protein and Peptide Analysis by Mass Spectrometry; In Methods in Molecular Biology; Chapman, J.R.; Ed. Humana Press: Totowa, NJ, 1996; pp 9-28.

24. Plaza, A.; Bifulco, G.; Masullo, M.; Lloyd, J. R.; Keffer, J. L.; Colin, P. L.; Hooper, J. N.; Bell, L. J.; Bewley, C. A. Mutremdamide A and Koshikamides C-H, Peptide Inhibitors of HIV-1 Entry from Different Theonella Species. J. Org. Chem. 2010, 132, 9069-9077.

25. Asakawa, Y.; Tokida, N.; Ozawa, C.; Ishiba, M.; Tagaya, O.; Asakawa, N. Suppression Effects of Carbonate on the Interaction between Stainless Steel and Phosphate Groups of Phosphate Compounds in HighPerformance Liquid Chromatography and Electrospray Ionization Mass Spectrometry. J. Chromatogr. A 2008, 1198/1199, 80-86.

26. Kim, J.; Camp, D. G. II; Smith, R. D. Improved Detection of MultiPhosphorylated Peptides in the Presence of Phosphoric Acid in Liquid Chromatography/Mass Spectrometry. J. Mass Spectrom. 2004, 39, 208 215.

27. Tuytten, R.; Lemiere, F.; Witters, E.; Van Dongen, W.; Slegers, H.; Newton, R. P.; Van Onckelen, H.; Esmans, E. L. Stainless Steel Electrospray Probe: A Dead End for Phosphorylated Organic Compounds? I. Chromatogr. A 2006, 1104, 209-221.

28. Liu, S.; Zhang, C.; Campbell, J. L.; Zhang, H.; Yeung, K. K.; Han, V. K.; Lajoie, G. A. Formation of Phosphopeptide-Metal Ion Complexes in
Liquid Chromatography/Electrospray Mass Spectrometry and Their Influence on Phosphopeptide Detection. Rapid Commun. Mass Spectrom. 2005, 19, 2747-2756.

29. Geiger, T.; Cox, J.; Mann, M. Proteomics on an Orbitrap Benchtop Mass Spectrometer Using All Ion Fragmentation. Mol. Cell. Proteom. 2010, in press.

30. Plumb, R. S.; Johnson, K. A.; Rainville, P.; Smith, B. W.; Wilson, I. D.; Castro-Perez, J. M.; Nicholson, J. K. Uplc/Ms(E): A New Approach for Generating Molecular Fragment Information for Biomarker Structure Elucidation. Rapid Commun. Mass Spectrom. 2006, 20, 1989-1994.

31. Wong, J. W.; Schwahn, A. B.; Downard, K. M. Etiseq-an Algorithm for Automated Elution Time Ion Sequencing of Concurrently Fragmented Peptides for Mass Spectrometry-Based Proteomics. BMC Bioinformatics 2009, 10, 244

32. Bagheri-Majdi, E.; Ke, Y. Y.; Orlova, G.; Chu, I. K.; Hopkinson, A. C.; Siu, K. W. M. Copper-Mediated Peptide Radical Ions in the Gas Phase. J. Phys. Chem. B 2004, 108, 11170-11181.

33. Chu, I. K.; Rodriguez, C. F.; Rodriguez, F.; Hopkinson, A. C.; Siu, K. W. M. Formation of Molecular Radical Cations of Enkephalin Derivatives Via Collision-Induced Dissociation of ElectrosprayGenerated Copper (II) Complex Ions of Amines and Peptides. J. Am. Soc. Mass Spectrom. 2001, 12, 1114-1119.

34. Karnezis, A.; Barlow, C. K.; O'Hair, R. A.; McFadyen, W. D. Peptide Derivatization as a Strategy to Form Fixed-Charge Peptide Radicals. Rapid Commun. Mass Spectrom. 2006, 20, 2865-2870.

35. Lam, C. N. W.; Siu, S. O.; Orlova, G.; Chu, I. K. Macrocyclic Effect of Auxiliary Ligand on the Gas-Phase Dissociation of Ternary Copper(II)Ggx Complexes. Rapid Commun. Mass Spectrom. 2006, 20, 790-796.

36. Laskin, J.; Yang, Z. B.; Lam, C.; Chu, I. K. Charge-Remote Fragmentation of Odd-Electron Peptide Ions. Anal. Chem. 2007, 79, 6607-6614.

37. Vaisar, T.; Gatlin, C. L.; Turecek, F. Oxidation of Peptide-Copper Complexes by Alkali Metal Cations in the Gas Phase. J. Am. Chem. Soc. 1996, 118, 5314-5315

38. Vaisar, T.; Gatlin, C. L.; Turecek, F. Metal-Ligand Redox Reactions in Gas-Phase Quaternary Peptide-Metal Complexes by Electrospray Ionization Mass Spectrometry. Int. J. Mass Spectrom. Ion Processes 1997, 162, 77-87.

39. Ramamoorthy, A. NMR Spectroscopy of Biological Solids; CRC/Taylor and Francis Group: Boca Raton, 2006; p. 353.

40. Paizs, B.; Suhai, S. Fragmentation Pathways of Protonated Peptides. Mass Spectrom. Rev. 2005, 24, 508-548.

41. Dodds, E. D.; Hagerman, P. J.; Lebrilla, C. B. Fragmentation of Singly Protonated Peptides Via a Combination of Infrared and Collisional Activation. Anal. Chem. 2006, 78, 8506-8511.

42. Burlet, O.; Orkiszewski, R. S.; Ballard, K. D.; Gaskell, S. J. Charge Promotion of Low-Energy Fragmentations of Peptide Ions. Rapid Commun. Mass Spectrom. 1992, 6, 658-662.

43. Dongre, A. R.; Jones, J. L.; Somogyi, A.; Wysocki, V. H. Influence of Peptide Composition, Gas-Phase Basicity, and Chemical Modification on Fragmentation Efficiency: Evidence for the Mobile Proton Model. J. Am. Chem. Soc. 1996, 118, 8365-8374.

44. Cooper, H. J. Investigation of the Presence of B Ions in Electron Capture Dissociation Mass Spectra. J. Am. Soc. Mass Spectrom. 2005, 16, 19321940.

45. Haselmann, K. F.; Schmidt, M. Do B-Ions Occur from Vibrational Excitation Upon H-Desorption in Electron Capture Dissociation? Rapid Commun. Mass Spectrom. 2007, 21, 1003-1008.

46. Lee, S.; Chung, G.; Kim, J.; Oh, H. B. Electron Capture Dissociation Mass Spectrometry of Peptide Cations Containing a Lysine Homologue: A Mobile Proton Model for Explaining the Observation of B-Type Product Ions. Rapid Commun. Mass Spectrom. 2006, 20, 3167-3175.

47. Lee, S.; Han, S. Y.; Lee, T. G.; Chung, G.; Lee, D.; Oh, H. B. Observation of Pronounced B*, Y Cleavages in the Electron Capture Dissociation Mass Spectrometry of Polyamidoamine (Pamam) Dendrimer Ions with Amide Functionalities. J. Am. Soc. Mass Spectrom. 2006, 17, 536-543.

48. Liu, H.; Hakansson, K. Abundant B-Type Ions Produced in Electron Capture Dissociation of Peptides without Basic Amino Acid Residues. J. Am. Soc. Mass Spectrom. 2007, 18, 2007-2013.

49. Bakken, V.; Helgaker, T.; Uggerud, E. Models of Fragmentations Induced by Electron Attachment to Protonated Peptides. Eur. J. Mass Spectrom. 2004, 10, 625-638.

50. Debois, D.; Giuliani, A.; Laprevote, O. Fragmentation Induced in Atmospheric Pressure Photoionization of Peptides. J. Mass Spectrom. 2006, 41, 1554-1560.

51. Delobel, A.; Halgand, F.; Laffranchise-Gosse, B.; Snijders, H.; Laprevote, O. Characterization of Hydrophobic Peptides by Atmospheric Pressure Photoionization-Mass Spectrometry and Tandem Mass Spectrometry. Anal. Chem. 2003, 75, 5961-5968.

52. Hakansson, K.; Cooper, H. J.; Emmett, M. R.; Costello, C. E.; Marshall A. G.; Nilsson, C. L. Electron Capture Dissociation and Infrared Multiphoton Dissociation Ms/Ms of an N-Glycosylated Tryptic Peptide to Yield Complementary Sequence Information. Anal. Chem. 2001, 73, 4530-4536.

53. Kelleher, R. L.; Zubarev, R. A.; Bush, K.; Furie, B.; Furie, B. C.; McLafferty, F. W.; Walsh, C. T. Localization of Labile Post-Translational Modifications by Electron Capture Dissociation: The Case of GammaCarboxyglutamic Acid. Anal. Chem. 1999, 71, 4250-4253.

54. Mirgorodskaya, E.; Roepstorff, P.; Zubarev, R. A. Localization of O-Glycosylation Sites in Peptides by Electron Capture Dissociation in a Fourier Transform Mass Spectrometer. Anal. Chem. 1999, 71, 4431-4436. 
55. Shi, S. D. H.; Hemling, M. E.; Carr, S. A.; Horn, D. M.; Lindh, I.; McLafferty, F. W. Phosphopeptide/Phosphoprotein Mapping by Electron Capture Dissociation Mass Spectrometry. Anal. Chem. 2001, 73, 19-22.

56. Syka, J. E. P.; Coon, J. J.; Schroeder, M. J.; Shabanowitz, J.; Hunt, D. F. Peptide and Protein Sequence Analysis by Electron Transfer Dissocia- tion Mass Spectrometry. Proc. Natl. Acad. Sci. U.S.A. 2004, 101, 9528-9533.

57. Sikanen, T.; Franssila, S.; Kauppila, T. J.; Kostiainen, R.; Kotiaho, T.; Ketola, R. A. Microchip Technology in Mass Spectrometry. Mass Spectrom. Rev. 2010, 29, 351-391. 